\title{
SOME OBSERVATION ON HUMAN CLAVICLE
}

\author{
Bilodi A K S ${ }^{1}$, Sinha B $\mathbf{N}^{1}$, Kumaran $\mathrm{S}^{1}$
}

\section{ABSTRACT}

The present study was done in the human clavicles that were available from department of Anatomy of Nepalgunj Medical College, Chasapani Nepal. Observations were made on length of the clavicle, mid shaft circumference cornoid tubercle Curvature index of the clavicles were also calculated. Results were analysed and discussed.

\section{Key Words: Mid shaft circumference-conoid-tubercle-curvature index, Subclavian groove, Trapezoid ridge.}

\section{INTRODUCTION}

Clavicle is morphologically distinct bone. It is the first bone to ossify. Begins its ossification in membrane with two primary centers of ossification. Clavicles are absent from forelimbs in ungolates and carnivores but are well developed in prehensile limbs in primates and in man. Terry (1932) Oliver (1951), Jit \& Singh (1966), Jit \& Sahani (1983) Singh \& Gangrade (1968 a \& b) Kaur (1997) have made detail study on clavicle both in India \& abroad.
In the present study: A random sample of 21 comprising 11 female \& 10 males clavicles from bone sets that were available form department of Anatomy of Nepalgunj Medical College, Chisapani were studied. The clavicles were grouped into male and female by the measurement of mid shaft circumference. One pair of the clavicle showed too much of curvature and prominent conoid tubercle. This made us to examine the clavicle as whole and noted the characters in different clavicles.

1. Nepalgunj Medical College, Chisapani, Banke, Nepal.

Address for correspondence : Dr. Arun Kumar S. Bilodi

Associate Professor of Anatomy

Nepalgunj Medical College, Chisapani, Banke

Nepal. 


\section{METHODS AND MATERIALS}

Both right and left clavicles were included in the study. Following measurement of a clavicle was made.

1. Length of the clavicle was measured by calipers putting 2 ends of the clavicle inside it and with the help of thread.

2. Curvature of the clavicle was measured by distance of curvature from the base line forming the 2 ends of medial $2 / 3$ sternal end of the clavicle to conoid tubercle.

3. Mid shaft curvature (minimum circumference) were measured to classify the clavicle into male and female categories by means of thread and calipers.

4. The sexing of the clavicle was also done by noting its weight in 2 sexes, where they were heavier in the males and lighter in females.

5. Muscular marking were noted in categories of mid, moderate, rough tubercles. Rough tubercle was measured as their height from the surface (bottom) and as regards to it Curvature were also classified into mild, moderate and highly curved by the measurement of curvature index.

Height of the curvature

Curvature index $=$ X 100

$$
\text { Length of the base }
$$

6. Observations were made and results were tabulated.

\section{OBSERVATION}

Male - 3 are on Left side, 7 on Right side

Female- 7 on Left side, 4 on Right sides

A. Conoid tubercle is very much prominent in the following clavicles.

- Three are having more prominent conoid tubercle on right side in female.

- Three are having prominent conoid tubercle on left side in female.
- One on right side in male and 18 on right side in female have more prominent conoid tubercle.

- One on left side in male has more prominent conoid tubercle.

Maximum curvature and prominent conoid tubercle are present one on left side and one on the right side of male of same body.

B. Curvature is larger in male and female.

Table I: Classification according to curvatures

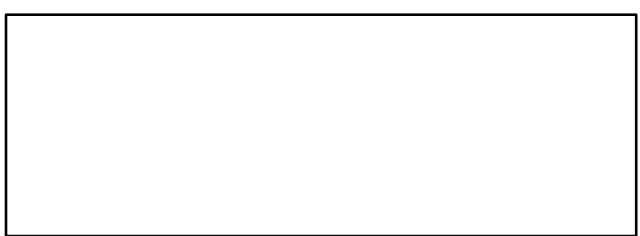

C. Table 2 shows the curvature index on both right and left clavicles.

\section{Tabel II : Curvature index of Clavicle}

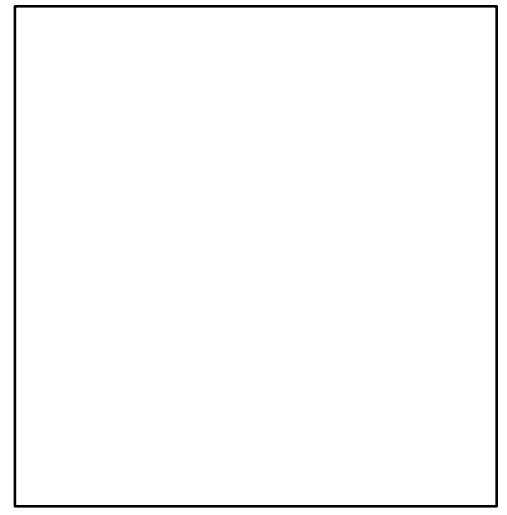

Length of clavicle is increased by interstitial growth of terminal cartilage, which are zones of hypertrophy and advance endochondral ossification.

Following are length of clavicle both on right side and left side measured by calipers. 
Table III : Length of Clavicle

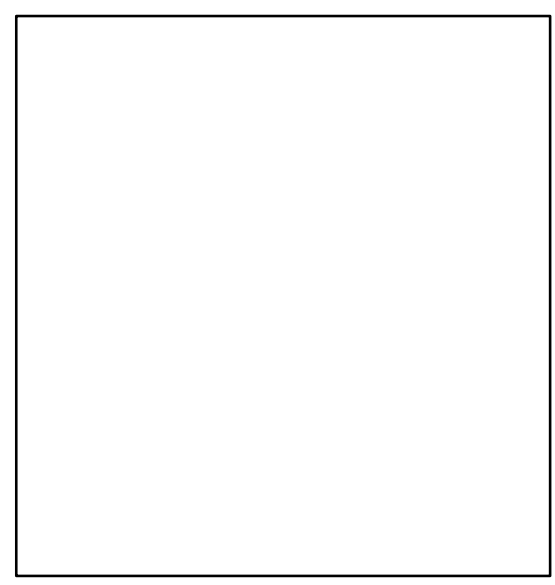

Average length of left clavicles is 12.49 and that of right clavicle is 13.4

\section{DISCUSSION}

A. 1. Female clavicle is less curved, thinner with less curvature \& smooth.

2. Acromial end is carried lower than sternal end but in males acromial end is slightly above.

3. In manual worker, muscular attachment are more marked with more curvature and thicker.

4. Mid shaft circumference is more reliable single indicter of sex.

5. Along with weight, length, and combination yield better results (OLIVIER 1951) (JIT \& SINGH 1966) (1)

B. Sahana also has related females clavicles are shorter, thinner and less curved with less
D. Mid shaft circumference is single indicator of sex (1) associated with weight and length that yields better result.

Table IV : Mid-shaft circumference

muscular markings, where as in male muscular markings are well marked (6).

Right clavicle in longer than left (4).

\section{In the Present study, the findings are:}

- Lengths of the clavicles are less than when compared to studies of Inderjit \& Shamer Singh. This may be due to material difference as in this study number of clavicles are " relatively Low"

- Weight of the female clavicle is slightly lower than in males in the present study but in studies of Inderjit \& Shamer Singh weight of female clavicles are very low

- Mid shaft circumference in female is also lower than male in the present study.

Table V : Length weight and mid clavicular circumference of the clavicles 
Length of the clavicle Oliver (1951) observed that left clavicle was longer than the right in French clavicles. Jit \& Singh (1966) also observed that left clavicle was longer than the right by $0.5 \mathrm{~mm}$. to $22.5 \mathrm{~cm}$ in Indian clavicles, of Amrithsar zone. Jit and Sahani (1983) made similar observation that left clavicle was longer than right in the $60 \%$ and both clavicles were of sane length in $30 \%$ of bones in Chandigargh zone. In Kaur etal (1997) studied clavicle in Patialia zone made similar observation in the present study (2000) Average length of right clavicles $144.2 \mathrm{~mm}$ are longer than left $(124.8 \mathrm{~mm})$.

Weight of the clavicle Weight of the clavicle also has given good results $36-65 \%$ in the study of clavicle by Kaur etal. This was conformed by Jit and Singh (1966), Singh and Gangrade (1968 b) and Jit and Sahani (1983). Inthe present study (2001) male clavicles are heavier with more muscular marking than in female. In females, clavicles are lighter and less muscular marking. (Table F)

Curvature - Harbir Kaur (1989) observed was that greater curvature in the right bones was responsible for short length than on left. In the present study three clavicles on right side are showing maximum curvatures and two on left side are showing maximum curbatures. There two bones one on each side (15 and 19) showing maximum curvatures with prominent conoid tubercle.

Mid clavicular circumference - Has given good results in male bones (30\% right side and $26 \%$ left side) but in case of female only $8 \%$ on right side and $6 \%$ left side were sexed by the study of Kaur etal. Present study the sex on the clavicles are known but it is more on RIGHT side than on LEFT side. ( $52.38 \%$ on right side and $47.62 \%$ on left side.)

\section{CONCLUSION}

In the present study only 4 measurements are taken to study 21 clavicles of known sex comprising 11 female and 10 males clavicles in this study.

1. Right clavicles are longer than left clavicles.

2. Male clavicles are heavier with more muscular markings than in female clavicles.

3. Mid clavicular circumference is less in female than in males.

4. Two clavicles are having maximum curvature and prominent conoid tubercle, which has made us to examine the clavicle as a whole and noted the characters in different clavicles. While other clavicles are having mild to moderate curvature on both sides. Hence the clavicles are studied and reported.

Clavicle may get fractured at junction of medial two third with that of lateral one third. In Cleidocranial dysostosis, there is coincidence of defect of ossification both intra membranous cranial bones as well as in the clavicle. Failure of two primary ossification centres may result in bony defect. This Knowledge of abnormal ossification helps in prevention of diagnosis of fracture in an otherwise normal clavicle.

\section{ACKNOWLEDGEMENT}

My sincere thanks to Managing director. Director of Lord Buddha Educational Academy. Principal, Head of Anatomy Department, Staff of Anatomy Department of Nepalgunj Medical College, Chisapani. My sincere thanks to Rara Computer Centre, Nepalgunj for secretarial help. 


\section{BIBLIOGRAPHY}

1. B anister $L$ awrence $H-G$ ray's $A$ natomy $\mid S E 38^{\text {th }}$ edition $C$ hurchill $L$ ivingstone $620 \mathrm{p}$.

2. J it I S ahani D (1983) S exing the $N$ orth I ndian clavicles. J ournal of the A natomical society of I ndia $32: 61-72$.

3. K .K aur, S iddhu.S .S ., K aushal.S, K aur.B .- S exing of $\mathrm{N}$ orth $\mathrm{W}$ est I ndian $\mathrm{A}$ dult $\mathrm{C}$ lavices of $\mathrm{P}$ atial $\mathrm{Z}$ one - J ournal of A natomical Society of I ndia (1997) $\mathrm{V}$ ol 46 (2)-121-140p.
4. $M$ oore $K$ eith. $L$ - C linically 0 riented $A$ natomy $-4^{\text {th }}$ edition- $L$ ippincott $W$ illiam and $W$ ilkin- $4^{\text {th }}$ edition (1999) 667-668p.

5. Singh $S, G$ angrade $K C$ (1968b) the sexing of adult $\mathrm{Clavicles:} \mathrm{demarking} \mathrm{points} \mathrm{for} \mathrm{V}$ aranasi $\mathrm{Z}$ one. J ournal of the anatomical $S$ ociety of I ndian 17:89100 .

6. Sahana's - H uman A natomy - Second special E dition K .K .P ublisher (1993) - 357 - 361p.

\section{Notice for Fund Raising}

The Journal of Nepal Medical Association (JNMA) is consolidating all its efforts in upgrading the quality of the Journal that could subsequently lead to international recognition and indexing. The necessary changes in editorial policy have already come into effect and activities (e.g., peer reviewing, copy editing, statistical review etc) pertaining to it have been initiated. However, the Journal is currently short in funds to effectively conduct these activities. Hence, fund raising has become inevitable but as to how best funds could be raised and mobilized is still a question. Among those thought of are creating a revolving fund and/or acquiring a physical facility and renting them out so that the incurred interest and/or rent could be utilized to support the activities.

In this regard the Journal looks forward to the opinions of its valued readers. Comments and queries may be forwarded to the Chief Editor of Journal. 